\title{
Unilateral abdominal protrusion as the main diagnostic sign of facioscapulohumeral dystrophy
}

\author{
Protrusão abdominal unilateral como principal sinal diagnóstico de \\ distrofia fáscio-escápulo-umeral
}

\begin{abstract}
André Macedo Serafim da Silva', Wagner Cid Palmeira Cavalcante1, Clara Gontijo Camelo', Rodrigo de Holanda Mendonça', Ida Fortini', Mary Souza de Carvalho', Edmar Zanoteli
\end{abstract}

A 48-year-old man presented with slowly progressive right arm weakness and cervical pain over the last 20 years. Previous electromyography/nerve conduction studies showed a neurogenic pattern on the right cervical myotomes and he received the diagnosis of focal motor neuron disease. No relevant family history was identified. On our initial evaluation, an asymmetrical abdominal protrusion was noted as well as a mild right arm weakness and atrophy (Figure), leading to the suspicion of facioscapulohumeral dystrophy (FSHD). A DNA test detected a D4Z4 repeat contraction on chromosome $4 \mathrm{qA}$, confirming the diagnosis. The frequency of an asymmetrical protuberant abdomen in these patients is not known. Although more than $80 \%$ of FSHD patients have affected abdominal muscles and $78 \%$ have some degree of asymmetry shown in MRI evaluation, less than $3 \%$ present with asymmetrical abdominal muscle involvement ${ }^{1}$. Even though it is an uncommon sign, the association of abdominal weakness and asymmetry is a key feature to consider FSHD diagnosis, especially in milder forms ${ }^{2}$.

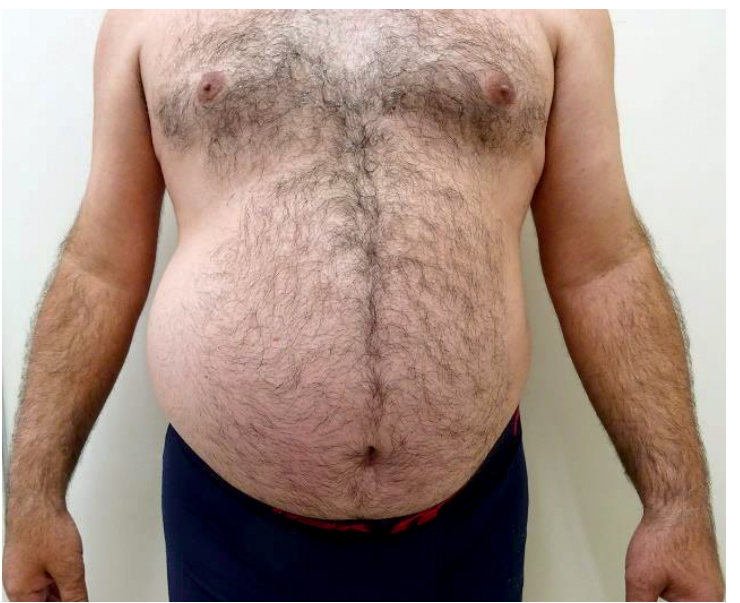

Figure. Right abdominal protuberance and right humeral atrophy.

\section{References}

1. Tasca G, Monforte M, Ottaviani P, Pelliccioni M, Frusciante R, Laschena $\mathrm{F}$ et al. Magnetic resonance imaging in a large cohort of facioscapulohumeral muscular dystrophy patients: Pattern refinement and implications for clinical trials. Ann Neurol. 2016;79(5):854-64. https://doi.org/10.1002/ana.24640
2. Mul K, Lassche S, Voermans NC, Padberg GW, Horlings CG, Engelen BG. What's in a name? The clinical features of facioscapulohumeral muscular dystrophy. Pract Neurol. 2016;16(3):201-7. https://doi.org/10.1136/practneurol-2015-001353

\footnotetext{
'Universidade de São Paulo, Faculdade de Medicina (FMUSP), Departamento de Neurologia, São Paulo SP, Brasil. 